Original Research Article

\title{
Pattern of adverse effects in patients with nephrotic syndrome on oral prednisolone
}

\author{
Shankareswari S. ${ }^{1}$, Jayapriya B. ${ }^{1 *}$, Balamurugan P. V. ${ }^{2}$, Lourdu Jafrin A. ${ }^{3}$, Geetha K. ${ }^{1}$
}

${ }^{1}$ Department of Pharmacology,

${ }^{2}$ Department of Medicine, Madurai Medical College, Madurai, Tamilnadu, India ${ }^{3}$ Department of Pharmacology, Indira Gandhi Medical College and Research Institute,

Pondicherry, India

Received: 20 April 2017

Accepted: 29 April 2017

*Correspondence to:

Dr. Jayapriya B.,

Email: jayapriyabalamurugan@ gmail.com

Copyright: (C) the author(s), publisher and licensee Medip Academy. This is an openaccess article distributed under the terms of the Creative Commons Attribution NonCommercial License, which permits unrestricted noncommercial use, distribution, and reproduction in any medium, provided the original work is properly cited.

\begin{abstract}
Background: Nephrotic syndrome is a common illness affecting the paediatric age group and $80 \%$ of the idiopathic syndrome is steroid sensitive. Multiple relapses make them vulnerable to the adverse effects of corticosteroids. There is limited literature evidence for the adverse effects of steroids in children with renal pathology.

Methods: This descriptive, cross sectional study analyses the adverse effects of oral prednisolone in children and adults with nephrotic syndrome Fifty-five patients with nephrotic syndrome, attending nephrology or paediatric OP, more than 3 years of age and who were on oral prednisolone for a minimum of eight weeks were included in the study. Demographic details, detailed history, lab investigations and ophthalmic examination were done and the results were analysed.
\end{abstract}

Results: Hypertension and behavioural changes were the most common adverse effects followed by dermatological, endocrine and metabolic changes. Infections and gastrointestinal disturbances were more in adults $(\mathrm{p}<0.05)$. Short stature was more in children $(\mathrm{p}<0.05)$. There was no abnormality in blood glucose levels and body weight. Hypertension, cushingoid habitus, infections and short stature were statistically less in patients on alternate day prednisolone. But no statistical association could be made between the occurrence of cataract and the pattern of prednisolone use.

Conclusions: Adverse effects pattern is different among adults and children. Also, the adverse effects are less with alternate day prednisolone regimen. Long term follow up into their adulthood is needed to analyse the morbidity produced by corticosteroids in these subsets of population.

Keywords: Adverse effects, Alternate day therapy, Corticosteroids, Nephrotic syndrome, Prednisolone

\section{INTRODUCTION}

Glucocorticoids, one of the hormones secreted by the adrenal cortex, have many physiological actions. Their potent immunosuppressive and anti-inflammatory properties make them one of the most used drugs. Since their introduction in 1948, they have never been given up or replaced. Their successful use, in fact is limited by its adverse reactions. Well documented adverse effects include immunosuppression, osteoporosis, hypertension, cushingoid features, HPA axis suppression and ocular complications. The use of glucocorticoids in children carries the additional risk of growth suppression, particularly during the growth spurts of infancy and adolescence. In this present study, the adverse effects of Prednisolone were analysed in nephrotic syndrome patients for three reasons.

- Glucocorticoids are the first line drugs for nephrotic syndrome as they reduce the mortality in childhood nephrotic syndrome from $35 \%$ to $3 \% .^{1}$ 
- Due to its relapsing nature, frequent administration of glucocorticoids is needed, so the adverse effects are also common,

- Both children and adults could be studied. Adverse effects of corticosteroids are particularly prevalent in those children who relapse frequently and thus require multiple courses of corticosteroids.

While current literatures document the adverse effects of glucocorticoid treatment in a wide spectrum of diseases, there are minimal data pertaining to nephrotic syndrome. The current study documents the adverse effects of oral Prednisolone in patients with nephrotic syndrome. Objectives of present study were to assess the adverse effects of oral prednisolone in nephrotic syndrome and to analyse the adverse effects in children and adults and their relation to the pattern of prednisolone use.

\section{METHODS}

After obtaining ethical clearance from the Institutional Ethical Committee, the study was conducted in the OutPatient Department of Nephrology and Paediatrics of Govt. Rajaji Hospital, Madurai. It is a descriptive cross sectional, single centre study, carried out from August 2010-November 2011. Total sample size was 55 patients which included both male and female.

Fifty-five patients above 3 years of age, who were on steroids for nephrotic syndrome for a minimum period of 8 weeks, were included in the study. Patients with other chronic ailments and those who were on concomitant medications like alternative medicines or immunosuppressant at any point during the course of illness were excluded from the study. After getting informed consent/assent from the patients, demographic and clinical data which included age, sex, duration of illness, duration of prednisolone therapy, concurrent medications including immunosuppressive, antihypertensive, anti-ulcer and anti dyslipidemic drugs, history of impaired wound healing, gastrointestinal irritation, insomnia, depression, aggression, history of fractures, history of infections including frequent respiratory tract infections, recurrent UTI, chicken pox, skin infections, cutaneous changes including acne, easy bruising were collected from the patients/parents and from their records. Height, weight and blood pressure were taken for all. Growth charts were used to determine the corresponding stature for age-sex percentile and the corresponding BMI for age sex percentile.

Stature less than $5^{\text {th }}$ percentile was considered as short, BMI at or above $85^{\text {th }}$ percentile and below $95^{\text {th }}$ percentile as overweight and BMI at or above $95^{\text {th }}$ percentile as obesity. $^{2}$ SBP and DBP $\geq 95^{\text {th }}$ percentile for gender, age and height on $\geq 3$ occasions was defined as hypertension. ${ }^{3}$ Ophthalmological examination by narrow beam slit lamp examination was done by ophthalmologists to look for cataract. A detailed clinical examination was done to look for the various adverse effects of steroid therapy.
Blood sample was collected during their next visit after overnight fasting for serum cholesterol and fasting blood sugar. Post prandial blood sugar was done at 2 hours. Fasting blood sugar more than $100 \mathrm{mg} \%$ and post prandial greater than $140 \mathrm{mg} \%$ was considered as abnormal. $^{4}$

\section{Statistical analysis}

Fisher exact test was used for analysis.

\section{RESULTS}

Among 55 patients, 30 were in pediatric age group and 25 were adults. Average age at the time of investigation was $12.2 \pm 4.26$ years. All patients were around 20 years of age (Figure 1).

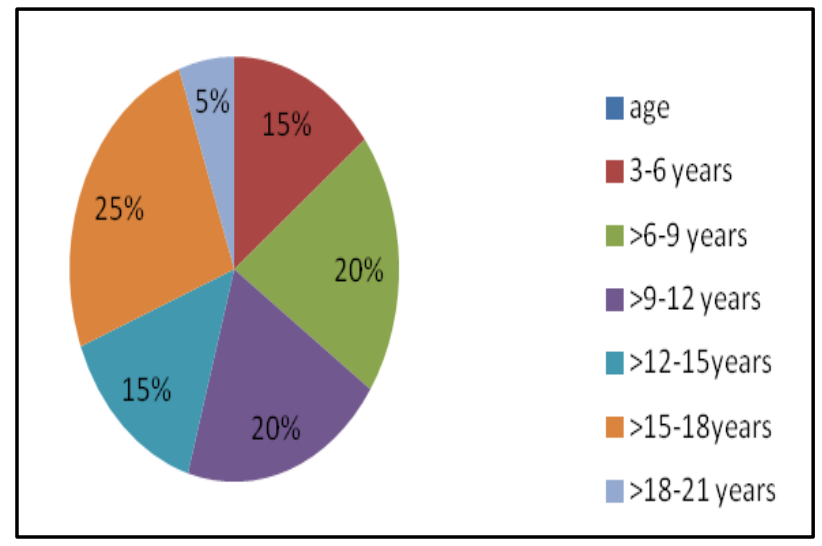

Figure 1: Age distribution of patients.

Mean age of onset of nephrotic syndrome in children was $5.53 \pm 1.07$ years and that in adults was $7.96 \pm 2.45$ years (Table 1).

Table 1: Age of onset of nephrotic syndrome in years.

\begin{tabular}{|lll|}
\hline $\begin{array}{l}\text { Age of onset } \\
\text { in years }\end{array}$ & $\begin{array}{l}\text { No of children } \\
(\mathbf{n}=\mathbf{3 0})\end{array}$ & $\begin{array}{l}\text { No of adults } \\
(\mathbf{n}=\mathbf{2 5})\end{array}$ \\
\hline $4-5$ & 16 & 3 \\
\hline $6-7$ & 13 & 8 \\
\hline $8-9$ & 1 & 9 \\
\hline $10-11$ & - & 2 \\
\hline $12-13$ & - & 1 \\
\hline $14-15$ & - & - \\
\hline $16-17$ & - & 2 \\
\hline
\end{tabular}

\section{Gender distribution}

Sixty percent of the study group was male and $40 \%$ were female. Male to female ratio was 2: 1 in children and 1.08:1 in adults. Overall, 34 patients were in daily prednisolone and 21 were on alternate day therapy. 11 children and 19 adults were frequent relapsers $(\mathrm{p}<0.01)$. 


\section{Age distribution of adverse effects}

Adverse effects observed were hypertension in 22 , behavioral changes in 22 (sleep disturbances in 9 and mood changes in 13) dermatological changes in 21 (thin skin 10, acne 8 and facial erythema 3 ) endocrine and metabolic changes in 21 (Cushingoid habitus 11, elevated cholesterol in 5 and menstrual irregularities in 3) infection in 18 , short stature in 15 , gastro intestinal disturbances in 10 and cataract in 6 patients. There was no significant weight gain in the study group.

Hypertension was observed in 9 (30\%) children and 13 $(52 \%)$ adults $(\mathrm{p}>0.058)$. Seven children and 10 adults were newly detected and others were on antihypertensive drugs. 4 of these patients were taking prednisolone on alternate days and 18 were on daily therapy $(p<0.02)$ (Table 2).

Table 2: Adverse effects of prednisolone in children and adults.

\begin{tabular}{|lll|}
\hline Adverse effect & $\begin{array}{l}\text { Age }<\text { 12 } \\
\text { years } \\
(\mathbf{n}=\mathbf{3 0})\end{array}$ & $\begin{array}{l}\text { Age }>\mathbf{1 2} \\
\text { years } \\
(\mathbf{n}=\mathbf{2 5})\end{array}$ \\
\hline Short stature & $12^{*}$ & 3 \\
\hline Hypertension & 9 & 13 \\
\hline Cataract & 3 & 3 \\
\hline Dermatological changes & 10 & 11 \\
\hline Behavioral changes & 10 & 12 \\
\hline Mood & 6 & 7 \\
\hline Sleep & 4 & 5 \\
\hline $\begin{array}{l}\text { Endocrine and metabolic } \\
\text { changes }\end{array}$ & 10 & 11 \\
\hline Cushingoid habitus & 8 & 3 \\
\hline Menstrual irregularities & 0 & 3 \\
\hline Elevated cholesterol & 2 & 3 \\
\hline Elevated blood sugars & - & - \\
\hline $\begin{array}{l}\text { Gastro intestinal } \\
\text { symptoms }\end{array}$ & 2 & $8^{*}$ \\
\hline Infections & 6 & $12^{*}$ \\
\hline * $<0.05$ & & \\
\hline
\end{tabular}

Infections were reported by $6(20 \%)$ children and 12 $(48 \%)$ adults $(p<0.05)$. In Children, the infections reported were upper respiratory tract infection and folliculitis. Adults had tinea, urinary tract infections, folliculitis, dental abscess, injection site abscess, cellulitis, chicken pox and respiratory tract infections. Those on daily therapy reported more infections ( $\mathrm{p}$ $<0.01)$.

Changes in sleep and mood were reported in both age groups ( $p>0.05$ ) $40 \%$ of the patients in the study group showed some disturbances of mood or sleep. Mood changes were reported in six children and seven adults. The changes described by mothers were irritability, excessive crying and need for more attention. Among the 6 children, 4 had aggravation of their behavioral problem on full dose of prednisolone. Adults complained of anger, depression and irritability. Sleep disturbances were reported in $16 \%$ of the study group, which includes 4 children and 5 adults. The Symptoms include insomnia as well as excessive sleep. Alternate day therapy did not alter this adverse effect ( $p>0.05$ ). Eight children (26\%) and 3 adults (12\%) had Cushingoid habitus. None of the patients on alternate day therapy had Cushingoid features ( $p<0.01$ ) Menstrual changes were reported in 3 adults. Two of them reported irregular cycles and one had amenorrhea for 6 months. Elevated cholesterol levels were observed in 2 children and 3 adults.

Table 3: Adverse effects and the pattern of prednisolone use.

\begin{tabular}{|lll|}
\hline Adverse effect & $\begin{array}{l}\text { Daily } \\
\text { prednisolone } \\
(\mathbf{n = 3 4 )}\end{array}$ & $\begin{array}{l}\text { Alternate day } \\
\text { prednisolone } \\
(\mathbf{n = 2 1})\end{array}$ \\
\hline Short stature & 15 & $2^{*}$ \\
\hline Hypertension & 18 & $4^{*}$ \\
\hline Cataract & 4 & 2 \\
\hline $\begin{array}{l}\text { Dermatological } \\
\text { changes }\end{array}$ & 17 & 4 \\
\hline Behavioral changes & 13 & 9 \\
\hline Mood & 7 & 6 \\
\hline Sleep & 6 & 3 \\
\hline $\begin{array}{l}\text { Endocrine and } \\
\text { metabolic changes }\end{array}$ & 18 & 3 \\
\hline Cushingoid habitus & 11 & 0 \\
\hline $\begin{array}{l}\text { Menstrual } \\
\text { irregularities }\end{array}$ & 2 & 1 \\
\hline Elevated cholesterol & 2 & 3 \\
\hline $\begin{array}{l}\text { Gastro intestinal } \\
\text { symptoms }\end{array}$ & 8 & 2 \\
\hline Infections & 16 & $2 * *$ \\
\hline$* p$ value $<0.05$ & $*$ palue $<0.01$ & \\
\hline
\end{tabular}

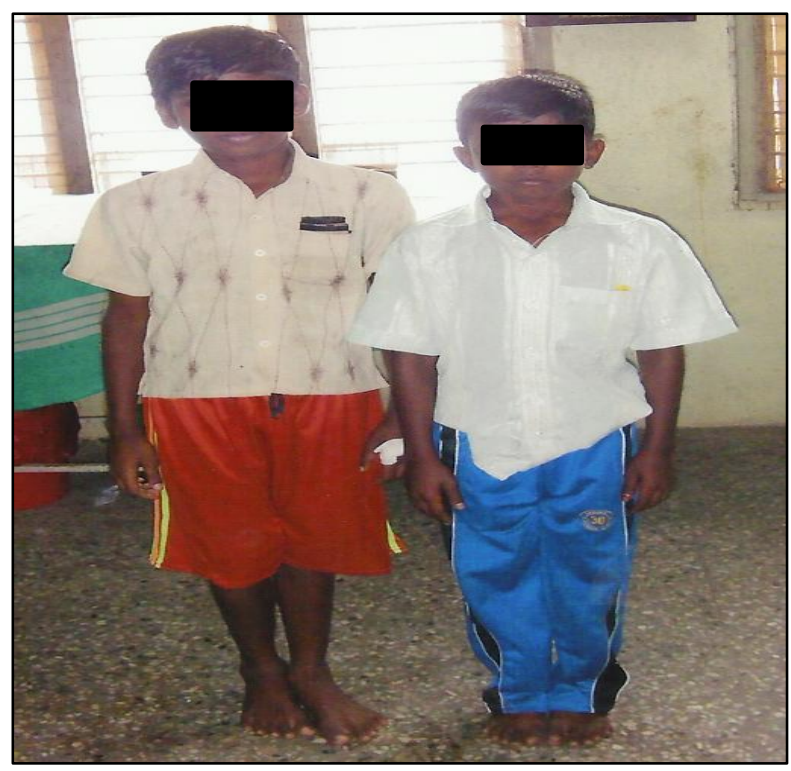

Figure 4: Short stature in 10-year-old males on prednisolone. 
Three children and three adults had posterior sub capsular cataract. Two of them had bilateral changes. Four of these patients were on Prednisolone daily and two were on alternate day therapy $(p>0.05)$. Some of the patients had visual symptoms (Table 3 ).

Fourteen $(36.6 \%)$ children and nine $(48 \%)$ adults showed dermatological changes $(p>0.05)$. The changes observed were acne, thin skin and facial erythema.

Gastrointestinal symptoms were reported in 2 (20\%) children and $8(48 \%)$ adults $(\mathrm{p}<0.05)$. These symptoms described by them were regurgitation, retrosternal discomfort and dyspepsia.

Twelve children and 3 adults were short statured ( $\mathrm{p}$ <0.05) 13 patients who took prednisolone daily were short whereas it was 2 in the alternate day therapy ( $p$ $<0.05$ ) (Figure 4).

History of fracture was reported by 1 adult male at the age of 17 years due to a trivial fall. Blood glucose levels revealed no significant changes in the study group.

\section{DISCUSSION}

The introduction of glucocorticoids has led to a significant reduction in mortality in nephrotic syndrome. Up to $70 \%$ of steroid sensitive nephrotic syndrome patients experience frequent relapses before a permanent remission, hence are exposed to steroids for a considerable period of time. The adverse effects of glucocorticoids are also well known. But most of the available data have not compared the pattern of adverse effects in children and adults. It is also sometimes difficult to differentiate whether the unfavorable outcomes are due to glucocorticoids or due to underlying disease or co morbidities.

The present study analyses the adverse effects of prednisolone in patients with nephrotic syndrome and its correlation with the pattern of prednisolone use in children and adults. Adverse events were found out both retrospectively and at the time of investigation and a detailed physical examination, blood sugar levels, cholesterol levels, ophthalmological examination were done at the time of the study. Analyzing the data, the present study showed that nephrotic syndrome was common in males among children and this predilection was not there in adults. Frequency of relapses was statistically more in adults than in children thus supporting the evidence that children respond better to corticosteroids. ${ }^{5}$ In the present study hypertension and behavioral changes were the more common adverse effects. Though hypertension is a common feature in glomerulonephritis and chronic kidney disease, it is not so in nephrotic syndrome. ${ }^{6}$ So the observed effect can be attributed to steroid intake. Literature evidence also reports an incidence of steroid induced hypertension as 10 to $40 \%$. Modulation of hypothalamo pituitary axis may be the key factor in increasing the cardio vascular risk. ${ }^{7}$ Corticosteroids also alter the brain excitability and levels of certain neurotransmitters. ${ }^{8}$ This explains the behavioral changes observed.

Dermatological, endocrine and metabolic changes were the next common adverse effects. Elevated cholesterol levels were observed in the study group but glucose levels revealed no abnormalities. Though steroids were known to increase blood glucose levels by $10-20 \%$ and frank diabetes is rare the counter regulatory hormones and the increased insulin secretion as evidenced by fasting hyperinsulinemia compensate for the corticosteroid induced insulin resistance. ${ }^{9,10}$ Though menstrual irregularities were not a prominent feature in iatrogenic Cushing's syndrome, in the present study, 3 adult females reported menstrual disturbances. ${ }^{11}$

Hypertension, Cushingoid habitus and behavioral changes were seen in children as well as adults and there was no statistical difference among them in the occurrence of these adverse effects. In adults, infections and gastrointestinal disturbances were more common and it was statistically significant. Short stature was observed in children and adults, but was statistically more in children. No significant change in stature in adults may be explained by the catch-up growth during the time of remission. ${ }^{12}$ The persistence of short stature in some may be due to glucocorticoids induced insulin like growth factor (IGF) resistance. ${ }^{13,14}$

The absence of significant weight gain in these patients may be due to

- Protein malnutrition resulting from urinary protein loss

- Dietary restriction followed by them due to salt restriction

- Steroid free interval during remissions.

Hypertension, Cushingoid habitus, infections and short stature were statistically less if the patients were on alternate day prednisolone. This is due to the better adrenal reserve in these patients. ${ }^{15-18}$

No Statistical association could be made between the occurrence of cataract and the pattern of prednisolone use or the two age groups. This supports the evidence that cataract development is not related to total does of steroid, duration of therapy and is seen even in alternate day therapy. ${ }^{19}$ The present study throws emphasis on the fact that children and adults are equally prone for adverse effects. Adverse effects were significantly less when steroids were given on alternate day regimen. So, careful adjustment of treatment regimens to achieve the lowest effective dose, the shortest duration of therapy and switching over to alternate day therapy whenever possible are the only options available to minimize the risks. A safer glucocorticoid should be developed which has full efficacy in anti-inflammatory activity, but with 
minimal adverse effects. The development of newer antiinflammatory agents that target the glucocorticoid receptor is also a potential option. And such a magical bullet would be a major benefit to the large number of patients suffering from the side effects of steroids, but who are in need of its anti-inflammatory activity to maintain their quality of life.

\section{ACKNOWLEDGMENTS}

Authors sincere thanks to Dr. R. Parameswari, M.D., Director and Professor, Head of the Institute of Pharmacology who gave encouragement for present study. Authors also extremely thankful to Dr. M. Shanthi, M.D., Professor of Pharmacology for her valuable suggestions and critical review at every stage for the successful completion of this study. Authors pay gratitude to Dr. Shanmuga Perumal, D.M., Professor and Head of the Department, Nephrology, Govt Rajaji Hospital, Madurai and Prof. Dr. P. Amutha Rajeshwari, M.D., D.C.H., Director, Institute of Child Health, Govt. Rajaji Hospital, Madurai for highlighting on the recent progress and development related to present work and guiding throughout the study. Authors express sincere thanks to Prof. Dr. Chitra Ayappan, M.D., D.C.H., for her guidance throughout the study.

\section{Funding: No funding sources}

Conflict of interest: None declared

Ethical approval: The study was approved by the Institutional Ethics Committee

\section{REFERENCES}

1. Hodson EM, Knight JF, Willis NS, Craig JC. Corticosteroid therapy in nephrotic syndrome: a meta-analysis of randomized controlled trials. Arch Dis Child. 2000;83:45-51.

2. 2000 CDC Growth charts for the United states: Methods and Development. Series 11, No. 246, http:// www.cdc.gov/ growth charts / cdc charts html.

3. Falkner B, Daniels SR, Flynn JT, Gidding S, Green LA, Ingelfinger JR et al. The fourth report on the diagnosis, evaluation, and treatment of high blood pressure in children and adolescents. Pediatr. 2004; 114:555-76.

4. Powers AC. Diabetes milletus. In: Harrisons principles of internal medicine. New York [etc.]: McGraw-Hill; 2012.

5. Kodner C. Nephrotic Syndrome in Adults: Diagnosis and Management. Am Fam Physician. 2009;80(10):1129-34.

6. Cameron JS. The nephrotic syndrome: Management, complications and pathophysiology. In (eds): Alex M, Davidson J, Cameron S, Pierre J, Girinfeld, Kerr DNS, Ritz E, Christopher G. Winerals Oxford text book of Clinical nephrology, $2^{\text {nd }}$ ed. Oxford Publication. 1998;1:461-92.
7. Shome GP, Sakauchi M, Yamane K, Takemura H, Kashiwagi H. Ischemic heart disease in systemic lupus erythematosus. a retrospective study of 65 patients treated with prednisolone. Japanese J Med. 1989;28(5):599-603.

8. Minetto MA, Botter A, Lanfranco F, Baldi M, Ghigo E, Arvat E. Muscle fiber conduction slowing and decreased levels of circulating muscle proteins after short-term dexamethasone administration in healthy subjects. J Clin Endocrinol Metab. 2010;95(4):166371.

9. Girod JP, Brotman DJ. Does altered glucocorticoid homeostasis increase cardiovascular risk? Cardiovascular Res. 2004;64: 217-26.

10. Peppa M, Krania M, Raptis SA. Hypertension and other morbidities with Cushing's syndrome associated with corticosteroids: a review. Integr Blood Press Control. 2011;4(3):7-16.

11. Seth A, Aggarwal A. Monitoring adverse reactions to steroid Therapy in Children. Indian Pediatr. 2004,;41:349-57.

12. Patel L, Clayton PE, Jenney ME, Ferguson JE, David TJ. Adult height in patients with childhood onset atopic dermatitis. Arch Dis Child. 1997;76:505-8.

13. Zhou X, Loke KY, Pillai CC, How HK, Yap HK, Lee KO. IGFs and IGF-binding proteins in short children with steroid-dependent nephrotic syndrome on chronic glucocorticoids: changes with 1 year exogenous GH. Europ J Endocrinol. 2001;144:23743.

14. Allen DB, Julius JR, Breen TJ, Attie KM. Treatment of Glucocorticoid-Induced Growth Suppression with Growth Hormone. J Clin Endocrinol Metab. 1998;83:2824-9.

15. Carter ME, James VH. Effect of alternate-day, single dose, corticosteroid therapy on pituitary-adrenal function. Ann Rheum Dis. 1972;31:379-83.

16. Greenstone MA, Shaw AB. Alternate day corticosteroid causes alternate day hyperglycaemia. Postgraduate Med J. 1987;63:761-4.

17. Yamashita F, Funatsu T, Nagayama K, Arihiro H, Anan S. Evaluation of alternate-day steroid therapy for nephrotic syndrome in childhood. Kurume Med J. 1971;18(3):153-60.

18. Wales JK, Milner RD. Variation in lower leg growth with alternate day steroid treatment. Arch Disea Childhood. 1988;63(8):981-3.

19. Langman MJ, Lancashire RJ, Cheng KK, Stewart PM. Systemic hypertension and glaucoma: mechanisms in common and co-occurrence. $\mathrm{Br} \mathrm{J}$ Ophthalmol. 2005;89;960-3.

Cite this article as: Shankareswari S, Jayapriya B, Balamurugan PV, Jafrin LA, Geetha K. Pattern of adverse effects in patients with nephrotic syndrome on oral prednisolone. Int J Basic Clin Pharmacol 2017;6:1269-73. 